University of Nebraska - Lincoln

DigitalCommons@University of Nebraska - Lincoln

USDA National Wildlife Research Center - Staff Publications
U.S. Department of Agriculture: Animal and Plant Health Inspection Service

September 2007

\title{
Population biology and monitoring of the Cuban hutia at Guantanamo Bay, Cuba
}

Gary W. Witmer

USDA-APHIS-Wildlife Services, gary.w.witmer@usda.gov

Martin Lowney

USDA Wildlife Services

Follow this and additional works at: https://digitalcommons.unl.edu/icwdm_usdanwrc

Part of the Environmental Sciences Commons

Witmer, Gary W. and Lowney, Martin, "Population biology and monitoring of the Cuban hutia at Guantanamo Bay, Cuba" (2007). USDA National Wildlife Research Center - Staff Publications. 731. https://digitalcommons.unl.edu/icwdm_usdanwrc/731

This Article is brought to you for free and open access by the U.S. Department of Agriculture: Animal and Plant Health Inspection Service at DigitalCommons@University of Nebraska - Lincoln. It has been accepted for inclusion in USDA National Wildlife Research Center - Staff Publications by an authorized administrator of DigitalCommons@University of Nebraska - Lincoln. 


\section{Population biology and monitoring of the Cuban hutia at Guantanamo Bay, Cuba}

\author{
Gary W. Witmer ${ }^{1, *}$ and Martin Lowney ${ }^{2}$ \\ 1 USDA National Wildlife Research Center, 4101 LaPorte \\ Avenue, Fort Collins, CO 80521-2154, USA, \\ e-mail: gary.w.witmer@aphis.usda.gov \\ 2 USDA Wildlife Services, P.O. Box 130, 21425 Hull \\ Street Road, Moseley, VA 23120, USA \\ ${ }^{*}$ Corresponding author
}

\begin{abstract}
The Cuban hutia (Capromys pilorides) is the largest native mammal occurring in Cuba. Endemic to the West Indies, most species of hutia are rare or extinct because of overharvesting, exotic species introductions, and habitat modifications by humans. An exception is Guantanamo Bay, Cuba, where the Cuban hutia is very common and is responsible for a variety of damage and conflicts, including damage to landscaping, gnawing through cables, damage to vehicles, the accumulation of large amounts of feces in residential areas, and damage to native vegetation, with little subsequent regeneration of many plant species. Current management focuses on population reduction by shooting and some trapping, followed by euthanasia or relocation to remote areas. There is little published information on the Cuban hutia. We present information on the biology of the hutia, along with population monitoring results from field studies at Guantanamo Bay, Cuba in 2001-2003. We found that the hutia is quite prolific and well adapted to exploit most habitats and plant foods. It appears that population sizes are greater in remote areas than in developed areas, but are nonetheless widespread and sizeable in all areas, despite several years of population control. However, even in areas of intense population control, hutia densities of $1-5 /$ ha are common. Management implications are discussed and several areas of additional data or research needs are identified.
\end{abstract}

Keywords: Capromys pilorides; Caribbean Sea; Cuba; damage; hutia; rodent; wildlife management.

\section{Introduction}

Although Cuba has a rich flora and avian fauna, it has few native mammals. Of the 77 native mammalian species, $>80 \%$ are extinct (Woods 1989, Woods and Eisenberg 1989). Bats comprise the largest mammalian species group on the island, with 33 species identified (both living and extinct). Rodents comprise the next most common mammalian species group. Historically, there have been as many as 21 species belonging to two subfamilies (Capromyinae and Heteropsomyinae), but only four species (all Capromys spp.) currently remain (Woods 1989). Human exploitation, habitat modification, and exotic species introductions have caused the demise of most species (Woods and Eisenberg 1989, Wing 1989). Most of the native mammalian species of Cuba are rare or endangered; of the terrestrial species, only the Cuban hutia (Capromys pilorides) is fairly common, especially in the area of Guantanamo Bay (GTMO) (IUCN 1982, Anderson and Jones 1984, Alvarez and Gonzalez 1991, Nowak 1991, Wilson and Reeder 1993).

Because of the rarity of capromyids, most human effort involves locating and protecting populations, including relocation and captive breeding programs (e.g., Clough 1985, Brochstein 1987, Alvarez and Gonzalez 1991). There is relatively little published in the literature on the hutia and some of the reports that are available are in Spanish and located in Cuban journals that are not readily accessible outside of Cuba (e.g., Perez et al. 1994). Much of what is known about hutia comes from observations of captive populations held in zoos or universities; furthermore, the accounts in mammal books are usually very brief (e.g., Anderson and Jones 1984, Parker 1990, Nowak 1991, Wilson and Reeder 1993).

Rodents, whether native or non-native, can also cause considerable damage and problems for humans worldwide, with substantial resources expended every year to reduce such problems (Witmer et al. 1995). High densities of the Cuban hutia cause a variety of damage and conflicts at GTMO (Higginson and Howe 2001, Witmer et al. 2002). Hutia population control efforts (primarily by night spotlight shooting and some daylight shooting) has occurred since 2000 in an effort to reduce the population density to a level at which vegetation will begin to recover and other types of damage and hazards (e.g., vehicle damage, fecal accumulation) will be reduced (Public Works Department 2002, Lowney 2003). Hutia are native to Cuba and rare outside of GTMO, however, and a management strategy must be developed that will reduce damage and conflicts while protecting the long-term viability of the species.

\section{Background on hutia}

The following brief account of the biology and ecology of the Cuban hutia has been gleaned from the previous citations. The Cuban hutia is the largest of the living species of Capromys. Adults average approximately 4-7 kg with a total length of $55-60 \mathrm{~cm}$, of which approximately $15 \mathrm{~cm}$ is the thick, lightly haired, presumably prehensile tail. It is the largest living native mammal in Cuba. The fur consists of long, coarse guard hairs and moderately dense, softer underfur. Animals are variously colored from a whitish-gray to a buff to a reddish-brown to a rich, 
dark brown to almost black. The fur is lighter colored on the underside of the animal.

Hutia of various species are generally sexually mature at approximately 10 months. Based on observations of captive animals, it appears that females can breed and bear young throughout the year, but have a birth peak in June. Females undergo a 15-16-day estrus and have a gestation period of approximately 110-125 days. The young are very precocial and are fully weaned in approximately 150 days, although they sample vegetation within a few days after birth. Females have a pair of lateral thoracic mammae on each side that are well hidden in the fur of their sides. Females typically have one young during their first pregnancy, but usually bear two or three young (range 1-6) thereafter. Hutia may live for more than 8 years in captivity. Depending on the species, animals are usually solitary or found in family groups.

The Cuban hutia is primarily nocturnal, spending the days in trees, inside hollowed-out tree trunks, in dense grass, in rocky areas, or underground in natural openings. They forage on a variety of plant parts (bark, stems, leaves, flowers, fruit) of many species and may consume lizards. Presumably, they do not require free water. Cuban hutia use a wide variety of habitats from steep, rocky ocean cliffs to mud flats to grasslands to forests. The chief predators of hutia are humans, large birds of prey, Cuban boas (Epicrates angulifer), and introduced dogs and cats. The Cuban crocodile (Crocodylus rhombifer) may have been a significant predator of hutia, but this species is now very rare in Cuba. Hutia may feed on the bark that they strip from trees and may feed in gardens, but are not considered an agricultural pest, perhaps because of their rarity throughout most of Cuba.

A rapid ecological assessment (REA) of GTMO was conducted in 1999 (ProAmbiente and The Nature Conservancy 1999). In this survey, the only native terrestrial mammal confirmed was the Cuban hutia, which was described as "extremely abundant" at GTMO, presumably owing to a lack of hunting, low densities of natural predators, and an "unlimited" food supply. The REA team used transects to estimate an average hutia density of $6.5 /$ ha across four different habitats. They noted that their density estimates may be low, that the hutia population is widespread and very abundant, and that they calculated density estimates only because of the concern expressed by residents regarding the size of the hutia population. Although they noted that all the mammal species occurring at GTMO are considered "secure globally" according to The Nature Conservancy conservation ranking system, they identified a need to protect the native hutia because it is rare outside of GTMO. They also recommended that the population status should be evaluated periodically, especially since hutia population control measures may be necessary in some areas.

An assessment of plant damage (APD) by herbivores at GTMO was conducted in 2000 (Areces-Mallea 2000). The APD report documented the severe effects of foraging by hutia, feral goats, and introduced white-tailed deer on many of the native plant species of GTMO, from grasses and forbs to small and medium-sized trees and their seedlings. The author identified 47 species of plants that were browsed by hutia, nine of which appeared to be particularly palatable. Another group of 17 plant species were also heavily used, but the browsing could have been attributed to hutia, deer, and/or goats. Twelve of 19 natural plant communities, most of special conservation concern, were identified as being impacted by excessive browsing. It was recommended that the hutia population be reduced to a third or even a quarter of its current size and that it be maintained at a low density for at least 5 years to document plant recovery.

A hutia population management (HPM) report was completed for GTMO in 2001 (Higginson and Howe 2001). The HPM report documents increasing concern regarding damage to property and vegetation caused by the local hutia population. The authors conducted road transect surveys and reported anywhere from 4 to 111 (average 47) hutia sightings per transect mile, with more sightings generally observed in the more remote (less disturbed) areas and fewer sightings in the developed urban or residential areas. Fewer hutia were observed in the transect surveys of 1996 than in those of 1999-2000, but the earlier surveys were carried out somewhat differently. They also used mark-recapture techniques to estimate hutia densities of $3-5$ and $10-13 /$ ha in developed and remote areas, respectively.

A hutia monitoring protocol was established at GTMO to assess the effectiveness of hutia control efforts and to confirm that the hutia population was not being excessively controlled (Public Works Department 2002). This was deemed necessary because the hutia is an important, native element of the fauna of Cuba and, in particular, a food source for the Cuban pygmy owl (Glaucidium siju) and the Cuban boa. Between January and September 2002, fixed-width transect surveys were conducted along roads at night using spotlights. It was determined that 75 feet on either side of the road was the maximum distance that hutia could be reasonably reliably observed. Thus, densities were estimated as the number of hutia observed along the transect divided by transect length multiplied by the transect width (Public Works Department 2002). Using this formula, it was estimated that hutia densities varied from 1 to 9 hutia/ha and averaged 2/ha. Several potential problems with this method of population monitoring were noted: hutia are also controlled by the same method and hence may have become "light-shy"; vegetation is recovering with the reduced numbers of invasive herbivores (deer, goats) and hutia, and hence the visibility of hutia in tall grass is lower; and human error involved.

\section{Study area and methods}

The United States government manages an area of approximately 12,000 ha at GTMO, Cuba, of which approximately two-thirds (8000 ha) is terrestrial, with the remainder being aquatic and mud flats. Approximately half of the terrestrial area is on the highly developed (i.e., areas with high densities of roads and buildings, and much human activity) east side of the bay, while the area on the west side of the bay is very remote, with little development of any kind. Terrestrial habitats comprise mainly dry tropical scrub-forest (Areces-Mallea 2000). 
Operations to reduce hutia populations (conducted from a pick-up truck mostly at night with 0.22-caliber rifles and spotlights) during May 2001 were used to collect specimens for necropsy. Necropsies were performed on 57 adult hutia. Based on reproductive status, we defined adults as animals $\geq 3 \mathrm{~kg}$. Whole body weight, total length, tail length, hind foot length, and ear length were recorded, along with the reproduction status and numbers of embryos for females and the maximum testes length for males. The sex ratio (females/males) was also determined. During September 2003, 73 adults were collected and examined for reproductive status and sex ratio.

Hutia populations were monitored between 11 June and 17 September 2003. Population monitoring by chew block and track station index were conducted at six sites: three in developed areas (i.e., areas with high densities of roads and buildings, and much human activity) and three in remote areas on the east side of GTMO. In the developed areas, 14 stations (7 with a chew block and 7 with a track station) were established along the transect at each site. Stations were approximately $10 \mathrm{~m}$ apart and alternated a chew block station with a track station. Transects were situated along the edge, where mowed areas (or road, right of way, fence line) interfaced with the taller grass and shrubs of undisturbed vegetation. Stations were generally set where there was evidence of a hutia runway coming out of the tall grass or under the fence and/or evidence of hutia fecal pellets. Chew blocks contained an attractive rodent food (steam-rolled oats) in a wax matrix and had a vertical hole drilled through them; each weighed approximately $58 \mathrm{~g}$. A wire flag was placed through the block and pushed into the ground to secure the block to the site. Each flag was labeled with the station number. Tracking tiles were white vinyl floor tiles of $30 \mathrm{~cm} \times 30 \mathrm{~cm}$. One half of each tile was coated with black oil-based printer's ink mixed with some mineral oil to prevent overnight drying of the ink. As animals crossed from the inked half to the clean half, footprints were deposited. Each track station was marked by a labeled wire flag placed nearby. Stations were placed in the afternoon and read the next morning. Presence was recorded if there was any evidence that one or more hutia had visited the station. Any amount of gnawing on the chew block not clearly caused by ants was assumed to be due to hutia. Any signs of hutia (tracks, pellets, urine) at the track station were considered evidence of a visit by one or more hutia. Disturbed or damaged chew blocks or track stations were replaced and read again on a second consecutive day. Two transects in the developed areas were operated from 11 to 13 June and one transect between 13 and 15 June 2003.

The chew block and track station surveys in the more remote areas were conducted two months later as described above with a few exceptions. Only 10 stations ( 5 with a chew block and 5 with a track station) were used for each transect. A different type of chew block was used (cornmeal in a wax matrix). The blocks were also smaller, so that two blocks were stacked and used at each station for a total of approximately $40 \mathrm{~g}$ at each station. These transects were monitored from 8 to 10 August 2003.
Population monitoring by mark-recapture [LincolnPetersen (L-P) index, as modified by Chapman to lessen bias; Lancia et al. 1994] was conducted at 33 sites: 25 sites were considered developed areas, whereas eight sites were considered remote areas. All but three sites were on the east side of GTMO. On the west side of GTMO, one transect was in a remote area and two were in developed areas. Each transect consisted of six cage traps spaced approximately $10 \mathrm{~m}$ apart. As with the chew block and track stations, an effort was made to place each trap near a hutia runway or other hutia sign such as fecal pellets. Traps were baited with discarded fruit and/or vegetables and set in the afternoon. They were checked early the next morning. Traps were operated for three consecutive nights, although we continued trapping for an additional 1-2 nights if unmarked hutia were still captured on the third day. Captured animals were weighed and their sex was determined. Rumps were spray-painted with a bright (yellow or orange) paint as a method of short-term marking before release at the site of capture. Animals were recorded as a "capture" (new animal) or "recapture" (a previously marked animal).

Another index, the minimum number known alive (MKA), was also used at all trapping sites (Yang et al. 1970). This method uses the total number of unique animals captured (i.e., not recaptures). The index gives a conservative estimate because, as a general rule, not all animals in the area will be captured at least once during the brief trapping period.

We also used the catch-per-unit-effort method (Lancia et al. 1994) to estimate the total population of hutia at GTMO. This method is a simple linear regression of the monthly harvest (vertical axis) plotted against the cumulative harvest (horizontal axis); the intercept of the line with the horizontal axis is the total population.

\section{Results}

\section{Biological parameters}

During the trip in May 2001, on both day and night excursions, hutia were abundant and were observed in all habitats (ocean cliffs, mud flats, grasslands, forest, and residential areas) on both the east and west sides of GTMO. The animals were observed "resting" in trees during the day and foraging on the ground at night. Their signs (tracks, droppings, and incisor marks on trees) were visible almost everywhere. They appear to live in extended family groups of 10 or more individuals (adults and young of both sexes).

On average, weights were lower and standard body measurements were greater than those reported in the literature (Table 1). In general, the coefficients of variation were relatively low, except for the number of embryos per female (Table 1). The sex ratio of the sample collected in May 2001 was somewhat skewed towards females, at 1.4 females per male. Although adult males were somewhat larger than adult females, the species does not appear to be sexually dimorphic. A wide variety of pelt colors was observed. Based on weights, measurements, and colors, animals from either the east or west side of GTMO were very similar. All animals appeared to be 


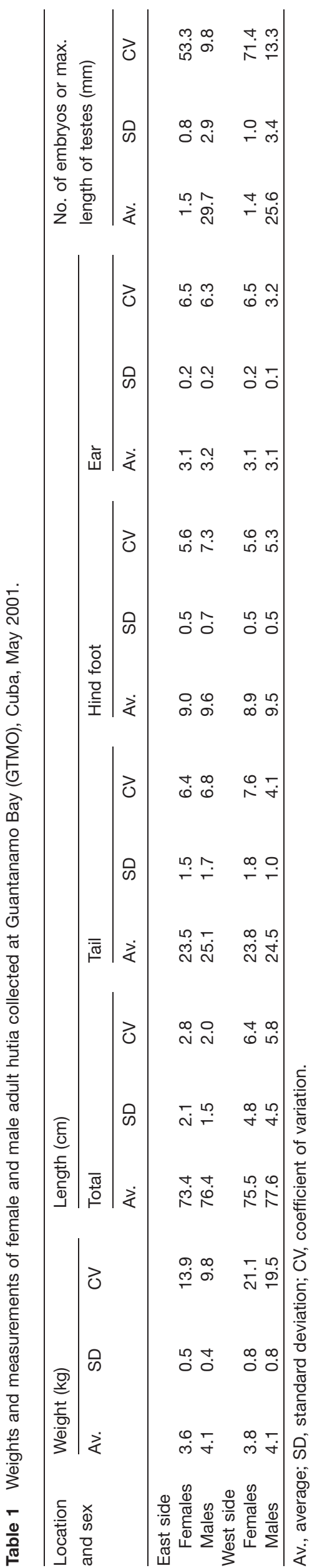

healthy and no external or internal parasites were noted. A few animals were missing a portion of their tails. All stomachs were full of a finely ground/digested green plant material, usually dark green, but at times some bright green or yellow material was visible. As an interesting observation, all individuals had lacerated or dissected livers. Twenty-two of 26 adult females (84.6\%) were pregnant, averaging 1.7 embryos per pregnant female. Females were at all stages of pregnancy, suggesting that reproduction may occur throughout the year. In addition, some females were both lactating and in the early stages of pregnancy, suggesting that they might have the potential to produce two litters per year.

Animals collected in September 2003 also appeared to be healthy. The sex ratio of animals live-trapped and shot in 2003, however, favored males (by at least 2:1). This change in sex ratio may be the result of control efforts if females are more likely to be shot than males. A lower percentage $(57.4 \%, 27$ of 47 examined) were pregnant in the September 2003 sample, suggesting that the reproductive peak was over. However, this still represents a high level of reproduction by females. Again, as in May, all stages of pregnancy were observed. Among the males examined in September 2003, 57.7\% (15 of 26 examined) were reproductively active, based on the size and development of the testes.

\section{Live-trapping results}

We captured 268 unique hutia (i.e., first-time captures, not counting recaptures) in 840 trap-nights conducted between 15 June and 17 September 2003. This corresponds to a $32 \%$ trap success rate, which is relatively high for rodent trapping. At least one hutia was captured at all 33 trap areas, so hutia still seem to be widespread at GTMO. Trap success was higher, however, in remote areas (93 unique hutia in 216 trap-nights; 43\% capture success) than in the more developed areas (175 unique hutia in 624 trap-nights; $28 \%$ capture success), suggesting that the relatively intense control efforts in developed areas are showing success in reducing hutia numbers.

We also recaptured 69 hutia for a total number of 337 hutia captures. This corresponds to an overall trap success rate of $40.1 \%$ (337 hutia in 840 trap-nights). Because hutia were readily recaptured, they do not appear to become trap-shy. Although the overall numbers of hutia recaptured seems somewhat low (69 of 337 total captures or $20.5 \%$ ), it must be remembered that the numbers of marked hutia available for capture remained low, albeit increasing somewhat with each night of trapping. Hence, the number of recaptures increased with each night of trapping: night 2, 8; night 3, 19; and night $4,36$.

We captured sizable numbers of unique hutia of both sexes and both age classes. Using only first-time captures, we captured 53 adult females, 85 adult males, 45 juvenile females, and 82 juvenile males. Across the sexes, it appears that adults and juveniles are equally likely to be captured (138 adults versus 127 juveniles). There was a tendency to capture more males (regardless of age) than females (167 versus 98). This is a common occurrence in mammals, since males are more far-rang- 
ing, more explorative, and more aggressive and, as a result, often suffer higher mortality rates. On the other hand, the higher capture rates for males may reflect a truly skewed sex ratio in the overall population. For example, of animals "randomly" shot during night control efforts, we noted that approximately 3-4 of every 5 animals shot was a male.

\section{Chew block and track tile station results}

These monitoring methods were able to detect varying amounts of hutia activity in both developed and remote areas; however, much more activity was detected in developed areas (Table 2). This may have resulted from the type of chew block used at the developed areas being more attractive or palatable to rodents, because the numbers of hutia as determined by trap success, L-P index, and MKA were all higher at the remote sites (Table 2). The L-P index and MKA seem to correlate well with the hutia activity levels at chew block and track tile stations in the remote areas, but not very well in the developed areas. Part of the problem with these indirect indices is that it is not always clear if the chewing or tracks are the result of hutia or other species of animals or if the activity is the result of one or several hutia.

\section{L-P index and MKA results}

At least one hutia was captured at each of the 33 sites live-trapped, resulting in MKA of $\geq 1$ for each site. The overall average MKA per site was 8.1 hutia. The average MKA was higher for remote areas (11.6) than for developed areas (7.0; Table 2). The L-P index could be calculated for all eight remote areas, but only for 16 of the 25 developed areas because there were no recaptures at nine developed areas. The overall L-P index average was 12.8 hutia per area live-trapped. As with the MKA, the L-P index was higher for remote areas (16.8) than for developed areas (9.6; Table 2). It is notable that the L-P index and MKA values seem to correlate relatively well. We note, however, that not all animals occurring in a given area were captured during the relatively brief livetrapping period for that area, so the MKA values are consistently lower than the L-P index values.

The hutia density in each of the trapped areas can be determined from the L-P index or the MKA values using an estimate of the home range size of a group of hutia. Based on radiotelemetry locations of radio-collared hutia, it has been estimated that a group of hutia use an area with a radius of approximately $250 \mathrm{~m}$ (Peter Tolson, Toledo Zoo, personal communication). This converts to a home range area of approximately 19.6 ha. The L-P index provides density estimates of approximately 0.7 hutia/ha. The more conservative MKA estimate (because not all animals occupying a given area were captured) is 0.6 hutia/ha.

\section{Catch per unit effort}

This analysis gave an estimated total hutia population in the area of heavy control (in the developed areas of the east side of GTMO) of 10,000 hutia. Because this area of control comprised an area of approximately 1785 ha, we estimated a density of 5.6 hutia/ha using this method. This value is substantially higher than the estimates obtained with both the L-P index and MKA methods $(\sim 1$ hutia/ha).

\section{Discussion and management implications}

It appears that hutia are still widespread and relatively abundant at GTMO. The results demonstrate that the chew block and track tile station methods could be used to monitor the presence and absence of hutia. The main advantage of these methods is their relative ease of implementation. On the other hand, the level of activity at these stations may not accurately reflect the actual numbers of hutia in the area in some cases.

Both the L-P index and MKA can be used to estimate hutia densities and the two methods seem to correlate well, although the nature of the MKA results in consistently lower (conservative) densities. However, these density estimates ( $<1$ hutia/ha) are much lower than those obtained by the catch-per-unit-effort method (5.6 hutia/ ha). This discrepancy suggests that further investigations are warranted to determine accurate methods for assessing the population of hutia at GTMO.

It was noted that hutia densities were lower in the developed areas than in the remote areas of GTMO. This could certainly be related to the more intensive control efforts in developed areas over the past several years. It can probably be assumed that animals will continue to move (i.e., disperse) into the lower-density, controlled areas from surrounding remote areas - this would be a classic example of source-sink dynamics. As such, it

Table 2 Population monitoring results for developed and remote areas of Guantanamo Bay, Cuba, 2003.

\begin{tabular}{|c|c|c|c|c|c|}
\hline Area & $\begin{array}{l}\text { Track tile } \\
\text { visits (\%) }\end{array}$ & $\begin{array}{l}\text { Chew block } \\
\text { visits (\%) }\end{array}$ & L-P index & MKA & $\begin{array}{l}\text { Catch per } \\
\text { unit effort }\end{array}$ \\
\hline Three developed areas & $83.3(11.2)$ & $85.7(7.5)$ & $\begin{array}{l}12.0 \\
D=0.6\end{array}$ & $\begin{array}{l}10.7(1.5) \\
D=0.5\end{array}$ & - \\
\hline Three remote areas & $26.6(30.6)$ & $23.3(25.2)$ & $\begin{array}{l}19.3(4.7) \\
D=0.9\end{array}$ & $\begin{array}{l}13.3(2.9) \\
D=0.7\end{array}$ & - \\
\hline All developed areas & - & - & $\begin{array}{c}9.6(4.2) \\
\mathrm{D}=0.5\end{array}$ & $\begin{array}{l}7.0(3.8) \\
\mathrm{D}=0.4\end{array}$ & $\begin{array}{l}10,000 \\
D=5.6\end{array}$ \\
\hline All remote areas & - & - & $\begin{array}{l}16.8(5.9) \\
D=0.9\end{array}$ & $\begin{array}{l}11.6(3.1) \\
D=0.6\end{array}$ & - \\
\hline
\end{tabular}

Results are presented as mean (standard deviation). Density estimates (D, hutia/ha) are also presented for methods capable of providing this parameter. 
might be wise to consider options for hutia management that would be less intensive and less costly than a continuous shooting program. Multiple-capture traps or rodenticide use are examples of two alternative approaches. Of course, all methods have advantages and disadvantages, and multiple methods often need to be combined in an integrated management strategy.

The biological data suggest that the GTMO hutia population is healthy and still very reproductive. The results suggest, however, that the level of reproduction later in the year (September) is lower than earlier in the year (May). There appears to have been a shift in sex ratio from one favoring females (determined in May 2001) to one favoring males (determined in September 2003). In mammals, sex ratios at birth are generally approximately $1: 1$. The ratio usually shifts in older animals to more females than males because of the higher mortality rate and greater dispersal tendency of males. Moreover, during unfavorable years (drought) or high population densities, females tend to produce more male offspring. On the other hand, females are often more secretive and less active when pregnant or caring for young, and may be less likely to be trapped or shot. It is not known which factor(s) is playing a role in the hutia sex ratio at GTMO.

Hutia population monitoring in 2003 , as reported here, suggests that hutia are still widespread and abundant at GTMO, especially on the east side of the Bay. It should be noted, however, that hutia appeared to be much less abundant during night work in 2003 than in 2001. This may be attributable to control efforts having reduced hutia numbers overall, but could also be related to lower visibility of hutia because of recovering vegetation and because of increased light and vehicle shyness of hutia after nearly 3 years of control by night spotlight shooting. While vegetation recovery from overgrazing by introduced (goat, deer) and native (hutia) herbivores is a goal of natural resource management at GTMO, the situation makes control and monitoring of hutia and invasive species more difficult. Vegetation recovery has not been quantified, but field personnel sense an increase in overall plant biomass and the number of young plants, as well as flowers and fruits. Some of this may be attributable to more favorable climatic conditions, but dramatic responses by vegetation after the removal of overabundant herbivores is commonly evident on islands. We observed this on Buck Island, US Virgin Islands, after the eradication of introduced roof rats (G. Witmer, unpublished data). In that situation, we also noted dramatic increases in nesting birds and in the lizard population. While we did not note increases in birds at GTMO in 2003, we were very impressed by the large numbers of lizards observed. It seems that many more young Cuban ground iguanas were observed than in 2001, when mostly larger individuals were observed. It can be assumed that diligent and persistent management of hutia and invasive species numbers will be required to continue this favorable progress towards the restoration of native ecosystems at GTMO. Surveys by experienced tropical botanists could determine whether or not key native tree and shrub species are regenerating adequately or if a program of native plant re-introduction is needed.
The hutia situation at GTMO is made more complex by the fact that we know relatively little about the biology and ecology of hutia, and the species has never been managed in the sense of modern-day wildlife management. Consequently, it is likely that there will be trial and error, research and data requirements, and a need for adaptive management. Because the species is rare throughout most of Cuba, an accurate monitoring program is essential to ensure that activities to reduce hutia damage do not result in long-term harm to the overall population at GTMO. For now, to allow the recovery of native vegetation and other faunal resources, managers will have to rely on hutia population reduction or means to exclude hutia from certain areas or resources.

\section{Acknowledgements}

We gratefully acknowledge the personnel of GTMO, especially Patricia Loop, Paul Schoenfeld, Les Popham, Amy Lambertsen, and Melissa Denfeld. We thank Peter Tolson for providing the hutia home range estimate used in our calculations. Michael Pipas and Richard Engeman also assisted with fieldwork.

\section{References}

Alvarez, V. and A. Gonzalez. 1991. The critical condition of hutias in Cuba. Oryx 25: 206-208.

Anderson, S. and J. Jones, eds. 1984. Orders and families of recent mammals of the world. John Wiley and Sons, New York. 686 pp.

Areces-Mallea, A. 2000. Assessment of herbivore damage in plant communities at U.S. Naval Station Guantanamo Bay, Cuba. Unpublished report for the Institute of Systematic Botany, The New York Botanical Garden, Bronx, New York. 29 pp.

Brochstein, B. 1987. The natural and zoological history of four Capromyid rodents. Anim. Keeper's Forum 14: 25-34.

Clough, G. 1985. A rather remarkable rodent. Anim. Kingdom 83: $41-45$

Higginson, D. and B. Howe. 2001. Hutia population management at U.S. Naval Station Guantanamo Bay, Cuba. Unpublished report for the Natural Resources Section, Naval Facilities Engineering Command, Norfolk, VA. 27 pp.

IUCN. 1982. The IUCN mammal red data book. International Union for the Conservation of Nature, Gland, Switzerland. $516 \mathrm{pp}$.

Lancia, R.A., J.D. Nichols and K.H. Pollock. 1994. Estimating the number of animals in wildlife populations. In: (T.A. Bookhout, ed.) Research and management techniques for wildlife and habitats. The Wildlife Society, Bethesda, MD. pp. 215-253.

Lowney, M. 2003. Invasive species report, Guantanamo Bay Naval Station, Cuba. Unpublished annual report for the United States Department of Agriculture, Wildlife Services, Moseley, VA. 12 pp.

Nowak, R. 1991. Walker's mammals of the world. 5th edition. The Johns Hopkins University Press, Baltimore, MD. 1629 pp.

Parker, S. ed. 1990. Grzimek's encyclopedia of mammals. Volume 3. McGraw-Hill Publishing Company, New York. 643 pp.

Perez, A., R. Paez and I. Garcia. 1994. Mesocapromys angelcabrerai (Varona, 1979), pequena jutia endemica de Cuba (Rodentia: Capromyidae). Cien. Biol. 26: 1-12.

ProAmbiente and The Nature Conservancy. 1999. Rapid ecological assessment of U.S. Naval Station Guantanamo Bay, Cuba. Unpublished report for The Nature Conservancy, Arlington, VA. 268 pp. 
Public Works Department. 2002. Hutia management. Unpublished report for the U.S. Naval Base, Guantanamo Bay, Cuba. $22 \mathrm{pp}$.

Wilson, D. and D. Reeder. 1993. Mammal species of the world. 2nd edition. Smithsonian Institution Press, Washington, DC. 1206 pp.

Wing, E. 1989. Human exploitation of animal resources in the Caribbean. In: (E.C. Woods, ed.) Biogeography of the West Indies: past, present, and future. Sandhill Crane Press, Gainesville, FL. pp. 137-152.

Witmer, G., M. Fall and L. Fiedler. 1995. Rodent control, research, and technology transfer. In: (J. Bissonette and P. Krausman, eds.) Integrating people and wildlife for a sustainable future. Proceedings of the 1st International Wildlife Management Congress. The Wildlife Society, Bethesda, MD. pp. 693-697.
Witmer, G., M. Lowney, H. McDaniel and D. Rees. 2002. Assessment of potential Cuban Hutia management at U.S. Naval Base, Guantanamo Bay, Cuba. Proc. Verteb. Pest Conf. 20: 59-66.

Woods, C. 1989. The biogeography of West Indian rodents. In: (C. Woods, ed.) Biogeography of the West Indies: past, present, and future. Sandhill Crane Press, Gainesville, FL. pp. 741-798.

Woods, C. and J. Eisenberg. 1989. The land mammals of Madagascar and the Greater Antilles: comparison and analyses. In: (C. Woods, ed.) Biogeography of the West Indies: past, present, and future. Sandhill Crane Press, Gainesville, FL. pp. 799-826.

Yang, K., C. Krebs and B. Keller. 1970. Sequential live-trapping and snap-trapping studies of Microtus populations. J. Mammal. 51: 517-526. 